\title{
A identidade de assistente social e atuação profissional em região de fronteira
}

\author{
The identity of the social officer and professional activities in the border region
}

\section{La identidad del oficial social y las actividades profesionales en la región fronteriza}

\author{
Natália Buginga Ramos da Costa Sachini ${ }^{1}$ \\ Mara Aline Ribeiro ${ }^{1}$
}

Recebido em: 08/02/2020; revisado e aprovado em: 04/10/2020; aceito em: 28/12/2020

DOI: http://dx.doi.org/10.20435/inter.v22i3.2927

\begin{abstract}
Resumo: A região fronteiriça é prenhe de contrastes e contradições, que envolvem, entre vários elementos, uma população com expressiva vulnerabilidade econômica e distintas relações sociais, culturais, econômicas e políticas. Nesse universo, o trabalho de assistência social toma dimensões distintas, por ser necessário o atendimento, também, às famílias estrangeiras, promovendo especificidades na atuação desses/as profissionais importantes de serem apontadas. As demandas atendidas em região fronteiriça ressignificam o exercício profissional de assistentes sociais, sendo indispensável repensar as práticas do serviço social junto a homens, mulheres e crianças que vivem e produzem na fronteira, dando origem a uma (re)definição das identidades, conforme será apresentada neste texto, que tem o objetivo geral de analisar a construção da identidade e atuação profissional da assistente social em uma região fronteiriça. A delimitação espacial do artigo é a fronteira Brasil/Bolívia, entre as cidades de Corumbá e Porto Quijarro. O caminho metodológico conta com levantamento bibliográfico, e optou-se por realizar a leitura, análise e interpretação da bibliografia que evidencia a temática em foco. O referencial teórico se apoia em estudiosos/as do Serviço Social e da Fronteira, por meio de outras ciências, como a Sociologia, a Geografia, a História e a Antropologia.
\end{abstract}

Palavras-chave: identidade; assistente social; fronteira.

Abstract: The border region is full of contrasts and contradictions, which involve, among various elements, a population with significant economic vulnerability and different social, cultural, economic, and political relations. In this universe, social assistance work takes on different dimensions because it is also necessary to serve foreign families, promoting specificities in the performance of these important professionals to be appointed. The demands met in the border region give new meaning to the professional practice of social workers, and it is essential to rethink social service practices with men, women, and children who live and produce on the border, giving rise to a (re)definition of identities, as will be presented in this text, which has as its general objective analyze the construction of the identity and professional performance of the social worker in a border region. The article's spatial delimitation is the Brazil/Bolivia border, between the cities of Corumbá and Porto Quijarro. The methodological path has a bibliographic survey, and it was decided to read, analyze, and interpret the bibliography that highlights the theme in focus. The theoretical framework is supported by scholars from Social Work and the Frontier through other sciences such as Sociology, Geography, History, and Anthropology.

Keywords: identity; social worker; border.

Resumen: La región fronteriza está llena de contrastes y contradicciones, que involucran, entre varios elementos, a una población con importante vulnerabilidad económica y diferentes relaciones sociales, culturales, económicas y políticas. En este universo, la labor asistencial adquiere diferentes dimensiones porque también es necesaria la atención a las familias extranjeras, promoviendo especificidades en el desempeño de estos importantes profesionales a nombrar. Las demandas atendidas en la región fronteriza dan un nuevo significado al ejercicio profesional de los trabajadores sociales, y es fundamental repensar las prácticas de servicio social con hombres, mujeres y niños que viven y producen en la frontera, dando lugar a una (re)definición de identidades, como se presentará en este texto, que tiene como objetivo general analizar la construcción de la identidad y desempeño profesional del trabajador social en una región fronteriza. La delimitación espacial del artículo es la frontera Brasil/Bolivia, entre las ciudades de Corumbá y Porto Quijarro. El recorrido metodológico cuenta con un relevamiento bibliográfico, y se decidió leer, analizar e interpretar la bibliografía que resalte el tema en foco. El marco teórico es apoyado por académicos del Trabajo Social y la Frontera, a través de otras ciencias, como Sociología, Geografía, Historia y Antropología.

Palabras clave: identidad; trabajador social; frontera.

\footnotetext{
${ }^{1}$ Universidade Federal de Mato Grosso do Sul (UFMS), Corumbá, Mato Grosso do Sul, Brasil.
} 


\section{INTRODUÇÃO}

O tema aqui proposto enseja reflexões e se configura na análise da construção da identidade do/a assistente social e sua atuação profissional, especificamente na cidade de Corumbá, localizada no estado de Mato Grosso do Sul, em uma região fronteiriça do Brasil com a Bolívia.

O presente estudo tem a intenção de promover uma discussão a respeito da identidade profissional no Serviço Social enquanto profissão regulamentada e inscrita na divisão sociotécnica do trabalho. A escolha por esta temática é fruto de inquietações e preocupações a partir da experiência vivenciada como assistente social junto à Secretaria Municipal de Assistência Social e Direitos Humanos no Município de Corumbá, atendendo pessoas em vulnerabilidade social que necessitam de serviços socioassistenciais.

A atuação dos/das assistentes sociais está pautada em posicionamentos teóricometodológicos e ético-políticos da profissão. E, à medida que o profissional está exercendo a profissão e desenvolvendo relações sociais, a identidade vai sendo construída, reconstruída, modificada, repensada em um processo de adaptação às demandas locais. Ela é modificada conforme o momento histórico e social vivido pelas pessoas que necessitam dos serviços sociais. É um movimento contínuo de reflexão sobre a própria prática profissional formada por processos muitas vezes contraditórios e dialéticos, os quais interferem diretamente na conduta dos sujeitos envolvidos no movimento de atendimento às pessoas e/ou famílias em situação de vulnerabilidade econômica.

As especificidades fronteiriças dinamizam o cotidiano do fazer profissional e reconstroem a identidade, considerando o fluxo intenso de imigrantes à procura de serviços socioassistenciais, em que se fazem necessárias estratégias de intervenção profissional para a garantia do acesso às políticas públicas e defesa dos direitos de cidadania social.

Entender o exercício profissional do/da assistente social e a construção da identidade diante das peculiaridades da fronteira viabilizará um debate sobre as competências teóricometodológicas pautadas em valores que fundamentam o projeto ético-político da profissão e das pessoas que optaram pelo Serviço Social como profissão.

De maneira geral, os espaços fronteiriços são áreas periféricas onde imperam desigualdades, comportando um conjunto de instituições, de práticas, de sujeitos e de modos de vida que atribuem características particulares a estes lugares, não presentes em outros (PEITER, 2005).

O recorte espacial da pesquisa abrange a análise da construção da identidade profissional da assistente social nas atividades desenvolvidas pelo Centro de Referência de Assistência Social (CRAS), de 2017 a 2019, vinculado à Secretaria Municipal de Assistência Social e Direitos Humanos de Corumbá, Mato Grosso do Sul (MS). Trata-se de um local público, localizado prioritariamente em áreas de maior fragilidade econômica, onde são oferecidos os serviços socioassistenciais, com o objetivo de fortalecer a convivência com a família e com a comunidade. A partir do adequado conhecimento do território do município de Corumbá, MS (bairros Cervejaria, Dom Bosco, Generoso, Borroviski, Beira Rio, Arthur Marinho), o Centro de Referência de Assistência Social (CRAS) promove a organização e articulação das unidades da rede socioassistencial e de outras políticas, possibilitando o acesso da população aos serviços, benefícios e projetos da assistência social, tornando-se uma referência para a população local e para os serviços setoriais.

A condição de assistente social e o exercício profissional no referido CRAS desencadearam inquietações e desejo de aprofundamento da construção de aspectos da identidade profissional. 
Para tanto, o artigo tem como objetivo geral analisar a construção da identidade e atuação profissional da assistente social em uma região fronteiriça. O caminho metodológico percorreu publicações de pesquisas científicas e levantamento bibliográfico sobre a temática.

A importância de essa temática ser discutida se respalda na dinâmica cotidiana estabelecida em uma fronteira onde os/as imigrantes recorrem frequentemente aos serviços socioassistenciais do Brasil.

Considerando a proximidade e a facilidade de acesso da população boliviana ao município de Corumbá, que se dá por vias terrestre e fluvial, e que, no Brasil, o sistema de assistência social é público e universal, a região tem elementos visíveis e invisíveis promotores de uma análise conceitual e científica do viver fronteiriço. Como bem destaca o autor Oliveira (2015):

Em se tratando das cidades de fronteiras, há um desconforto aparente e um confronto tácito entre as duas organizações. A condição bipolar e multiforme do território fronteiriço faz com que as organizações econômicas criem modelos próprios de intercâmbio, cada vez mais porosos, na circulação de bens, serviços e pessoas, todos no sentido de abrir flancos que assegurem a perene relação de trocas, gerando mais e mais relações horizontais. É lícito proferir que a atuação dos organismos econômicos consagra, grosso modo, o modus vivendi da comunidade com maior concisão. (OLIVEIRA, 2015, p. 238).

Entre os/as usuários/as atendidos/as no CRAS, estão os/as imigrantes com residência fixa em Corumbá, MS, e aqueles/as que declaram residir na cidade brasileira para terem acesso às políticas públicas, mas, na realidade, moram na Bolívia. Pode-se destacar também mulheres de nacionalidade boliviana residentes na fronteira que dão à luz na maternidade brasileira, visto que, no Brasil, o direito à saúde é universal e qualquer pessoa, independentemente de sua nacionalidade, pode ter acesso ao Sistema Único de Saúde (SUS), segundo a Constituição Federal de 1988, artigo 196. (BRASIL, 1988).

Nas multiplicidades fronteiriças entre o Brasil e a Bolívia, o viver em condições econômicas precárias, como no caso dos migrantes, fomenta a necessidade de políticas públicas por parte dos Estados nacionais envolvidos para atender brasileiros/as e bolivianos/as.

Para entender o fluxo de pessoas estrangeiras na cidade fronteiriça Corumbá, é importante destacar algumas características dessa região.

Na faixa de fronteira Brasil-Bolívia, constituída por dois municípios localizados no extremo oeste de Mato Grosso do Sul (Ladário e Corumbá) e dois municípios no extremo leste do Departamento de Santa Cruz (Puerto Quijarro e Puerto Suarez), a população estabelece múltiplas relações que movimentam a economia e a cultura, devido ao comércio, ao trabalho e à educação (SILVA; FERREIRA, 2013). O município de Corumbá encontra-se na região Centro-Oeste do Brasil, no Estado de Mato Grosso do Sul conforme ilustrado na imagem 1, em uma microrregião da Bacia do Baixo Pantanal, às margens do Rio Paraguai. 
Imagem 1 - Localização da fronteira Brasil-Bolívia

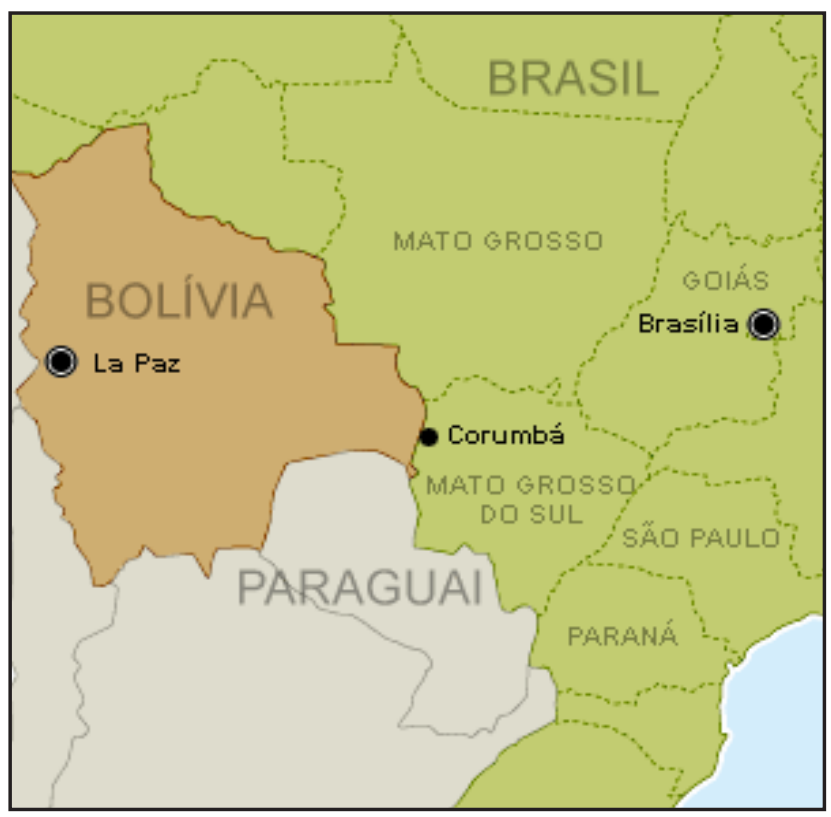

Fonte: UOL (2013).

Para conhecer melhor essa realidade, optou-se por realizar a leitura, análise e interpretação da bibliografia que evidencia a temática em foco.

O trabalho consiste em problematizar, por meio da discussão entre autores de diversas ciências, que oferecerão subsídios teóricos, sobretudo, do Serviço Social e dos Estudos sobre Fronteira, a ideia de uma construção identitária do profissional de serviço social, discorrendo sobre a intervenção profissional na região de fronteira na conurbação Corumbá/Ladário do lado brasileiro e Puerto Quijarro/Puerto Soares na porção boliviana.

\section{A (RE)CONSTRUÇÃO DA IDENTIDADE DA ASSISTENTE SOCIAL NA FRONTEIRA BRASIL/BOLÍVIA E SUA ATUAÇÃO PROFISSIONAL}

Ao iniciar uma discussão sobre identidade profissional, é importante reconhecer que o território é o componente principal da construção identitária. Independentemente da perspectiva, seja social, seja profissional, reconhecer-se perpassa pelo cotidiano e pela condição de vida das pessoas; além disso, está em constante processo de transformação.

A identidade se constitui no território a partir de vários elementos que se inter-relacionam e se completam, originando diferentes tipos de identidades, entre elas, a identidade profissional.

Para compreender a formação da identidade profissional da assistente social, é necessário entender primeiramente que o Serviço Social na atualidade é fruto e expressão de um amplo movimento de lutas pela democratização da sociedade, do Estado e do país, com forte presença das lutas operárias impulsionadas pela Ditadura Militar.

Foi nesse contexto de ascensão do movimento das classes populares, em torno da elaboração e aprovação da Constituição Federal de 1988 e da defesa do Estado de Direito, que a categoria dos/das Assistentes Sociais foi sendo questionada pela prática política de diferentes segmentos da sociedade e respondeu a esse processo ampliando e reformulando o horizonte 
de preocupações no âmbito do Serviço Social. Assim, revigorou-se uma fecunda organização da categoria em bases sindicais, acadêmicas e profissionais (IAMAMOTO, 2006).

Segundo a Lei de Regulamentação da Profissão (BRASIL, 1993), Inciso I Art. 4o, os/as assistentes sociais atuam diretamente vinculados às políticas sociais e têm como uma das competências a elaboração, implementação, execução e avaliação das políticas sociais, junto aos órgãos da administração pública direta ou indireta, empresas, entidades e organizações populares, possuindo competência teórico-metodológica para atuarem em todos os níveis e setores das políticas sociais. As/os profissionais de Serviço Social têm as competências voltadas para a execução terminal de políticas sociais, conforme costuma assinalar Netto (2001). Mas há de se considerar que, embora a função de executores terminais seja a prática predominante, ela não é exclusiva, tendo em vista as outras possibilidades profissionais postas e outras conquistadas pelos/as assistentes sociais.

Apesar de bem definidas as competências da assistente social, pouco se debate sobre os elementos que norteiam a construção da identidade profissional, como valores, objetivo, finalidade, corpo teórico-metodológico e a história, por exemplo.

No Serviço Social, a questão da identidade profissional segue basicamente duas linhas distintas. A primeira, defendida por Martinelli (1991), busca a identidade do Serviço Social na história da profissão, e, na segunda, Gentilli (1997) defende que a identidade profissional é construída na prática, em uma pluralidade de representações.

Os estudos de Martinelli (1991) foram guiados pelo referencial teórico marxista, no qual a identidade profissional é pensada de forma dialética, como categoria política, social e histórica, visando a compreender o Serviço Social na conjuntura brasileira. A autora ainda destaca que pensar dialeticamente é ver o processo histórico como dinâmico, sempre em movimento.

A identidade, enquanto elemento definidor da participação na divisão social do trabalho e na totalidade do processo social, é uma categoria política e sócio-histórica que se constrói na trama das relações sociais, no espaço social mais amplo da luta de classes e das contradições que a engendram e são por ela engendradas (MARTINELLI, 2000, p. 17).

Para a autora, as identidades se constroem e se objetivam na práxis, pela mediação das formas sociais de aparecer das profissões, e expressam as respostas construídas profissionalmente para atender às demandas que incidem no campo de ação. As identidades nunca estão prontas, transformam-se, assim como são modificadas as condições sócio-históricas em que se deu a estruturação.

Em um artigo mais recente, Martinelli (2013), na Revista Serviço Social \& Saúde, destaca a profissão como uma organização essencialmente dinâmica, de natureza interventiva, de trabalho coletivo, socialmente construído e partícipe do processo global de trabalho. A identidade é a expressão material e concreta da forma de ser da profissão. Portanto é uma condição de ser, é um campo aberto de possibilidades.

A questão da identidade profissional é também debatida por Gentilli (1997), que a aborda sob dois aspectos: o primeiro refere-se à diversidade de práticas existentes e o segundo corresponde a uma pluralidade de representações, que repercutem na identidade profissional. Para tanto, aborda as questões presentes no discurso das organizações e instituições formais da profissão, bem como em depoimentos dos próprios profissionais no mercado de trabalho.

A formação da assistente social perpassa por um processo de valorização da habilidade pessoal no exercício da profissão, além dos fatores sociais e políticos que definem o profissional, resultante da interação entre a dimensão formal (bases normativas da profissão, constituídas 
pelas unidades de ensino, os conselhos regionais e federal e centros de pesquisa) e informal da profissão.

Para Gentilli (1997), os produtos deste processo de trabalho profissional se expressam na forma de garantias dos direitos constitucionais, pelo acesso e pela efetivação desses direitos aos usuários dos serviços socioassistenciais. Ou seja, é dentro desta processualidade do trabalho que reside a lógica que configura a identidade profissional do Serviço Social.

O Serviço Social tem a prática como definidora da identidade profissional, a inserção profissional no mercado de trabalho se dá em um campo vasto. $E$, desta variedade que acontece na prática, é impossível demarcar a existência de uma identidade única, mas sim de diversas identidades.

Para Castells (2000), a construção da identidade é importante, pois está ligada a uma estrutura de poder em constante mutação, de interesses, de valores e de projetos, com base na experiência e estabelecendo uma relação entre natureza, história, geografia e cultura.

Ainda, Castells (2000) evidencia que:

Entende-se por identidade a fonte de significado e experiência de um povo, ou seja, o processo de construção de significado com base em um atributo cultural, ou ainda um conjunto de atributos culturais inter-relacionados, o(s) qual(ais) prevalece $(\mathrm{m})$ sobre outras fontes de significado. [...] Identidades por sua vez constituem fontes de significado para os próprios atores, por eles originadas, e construídas por um processo de individuação. (CASTELLS, 2000, p. 23).

A construção da identidade não é um processo imutável, ao contrário, é altamente dinâmico e resultante de uma relação dialógica entre indivíduo e sociedade.

É importante considerar a diferença entre identidade e papéis sociais, ressaltando que, enquanto os últimos "[...] são definidos por normas estruturadas pelas instituições e organizações da sociedade" (CASTELLS, 2002, p. 23), as identidades são construídas pelos próprios atores, por meio de um processo de individuação.

No que tange às políticas sociais, estas estão embasadas no princípio da municipalização; requisitam-se novas funções e competências à categoria, a qual é chamada para intervir também no âmbito da formulação, avaliação, planejamento e gestão de políticas, inseridos em equipes multiprofissionais.

Nas multiplicidades fronteiriças entre o Brasil e a Bolívia, o viver em condições econômicas precárias fomenta a necessidade de políticas públicas por parte dos Estados nacionais envolvidos para atender brasileiros/as e bolivianos/as.

Giovanella (2007) reitera que as regiões de fronteiras do Brasil têm se mostrado menos desenvolvidas, devido ao baixo status socioeconômico relacionado à desigualdade social. As ideias da autora vão ao encontro da perspectiva do trabalho do/da assistente social como peça fundamental para o atendimento dos sujeitos desta pesquisa, porque, segundo Filartigas (2014), os bolivianos deslocam-se espontaneamente para o país e não pretendem ficar definitivamente, sendo, portanto, uma migração temporária. O principal motivo do deslocamento é o econômico e envolve a perspectiva de trabalho e melhores condições de renda.

Os/as bolivianos/as emigram para o Brasil em busca de trabalho, com a esperança de economizar dinheiro e retornar para seu país, a fim de proporcionar melhores condições de vida para a sua família (FILARTIGAS, 2014). 
É comum o movimento pendular diário na fronteira, para trabalhar durante o dia e retornar para o país de origem após o expediente. Pode-se observar imigrantes bolivianos/as, em condição pendular na cidade de Corumbá, MS. Além do trabalho, o atendimento no âmbito da saúde, educação e assistência social impulsionam o trânsito de pessoas entre os países.

Aquela distinção entre limites e fronteiras pode ser verificada em diversas circunstâncias naquela cidade, como, por exemplo, a frequência com que constatamos a existência de imigrações pendulares na fronteira que envolve Corumbá. Notamos o fluxo diário de pessoas que trabalham, estudam e/ou empreendem na Bolívia e retornam aos seus lares no Brasil. Da mesma maneira, isso ocorre no sentido inverso. É de relativa facilidade constatar que esses imigrantes pendulares fazem uso dos recursos que a vida de fronteira proporciona para adequarem-se às normas e leis impostas pela existência dos limites internacionais. Falamos aqui de braçais que trabalham com changa, caminhoneiros, comerciantes, feirantes, ambulantes, estudantes, entre outros, que cruzam o limite, senão diariamente, entre o Brasil e a Bolívia para trabalhar, fazer seus negócios e estudar. E, seguindo a marcação feita por Foucher, essa fronteira é do tipo aberta, o que facilita o fluxo cotidiano e rotineiro de pessoas e mercadorias. (OLIVEIRA; CORRÊIA; OLIVEIRA, 2017, p. 98).

Considerando o espaço fronteiriço rico em diversidade, repleto de conflitos sociais, com uma dinâmica histórica própria e experiências concretas renovadas constantemente, concebe-se necessária a atenção sobre as questões da fronteira, envolvidas com a legitimidade dos direitos sociais e, consequentemente, com as ações profissionais dos/as assistentes sociais, já que estes aparecem como profissionais atuantes na viabilização de direitos de cidadania.

Na atualidade, a fronteira é palco de tripla tipificação da imigração de brasileiros e bolivianos e outras nacionalidades: os permanentes, que emigraram para o país vizinho ao seu, e lá se estabeleceram; os de passagem, que fazem uso da fronteira como uma instância deliberativa para seu ingresso; e os pendulares, que desenvolvem atividades empreendedoras, laborais ou estudantis no país vizinho, retornando para seu país de origem rotineiramente (CORRÊA, 2016).

Neste aspecto, Corumbá exerce papel central, uma vez que os movimentos pendulares estão estabelecidos naquela cidade em direção a todas as outras e em via dupla (LOIO; MARINI; OLIVEIRA, 2017). E, no que diz respeito a esta Dissertação, são os pendulares bolivianos que prevalecem na cidade, embora, nesse processo, fazem também parte os brasileiros, peruanos e colombianos, nigerianos, chilenos e argentinos que residem na Bolívia, além dos brasileiros e bolivianos que vivem do lado brasileiro.

Sob essa percepção de mobilidade humana, a mudança de país buscando melhores condições de ganho em atividade remunerada e, por muitas vezes, enfrentando a estigmatização de pessoas e funcionários das políticas públicas sobre a premissa de que se trata de não nacional, um "problema social", que o trabalho do/a assistente social tem papel ético-político de intervir e lutar pelos direitos desses cidadãos, sob o desafio do pensamento e da lógica do Estado.

Hofling (2001) conceitua as políticas públicas aquelas compreendidas como as de responsabilidade do Estado quanto à implementação e manutenção a partir de um processo de tomada de decisões que envolvem órgãos públicos e diferentes organismos e agentes da sociedade, relacionados à política implementada.

A Política de Assistência Social estabelece princípios e diretrizes norteadoras por meio do Sistema Único de Assistência Social (SUAS), que reorganiza os serviços, programas, projetos e benefícios relativos à assistência social, considerando as cidadãs e os cidadãos que dela necessitam. 
Com isso, o Serviço Social, profissão inscrita na divisão social e técnica do trabalho, chegou à última década com o entendimento de uma profissão crítica e propositiva, atuando nas múltiplas expressões da "questão social" por meio de políticas sociais públicas e privadas, de organizações da sociedade civil e de movimentos sociais. Nestes espaços, como profissionais dotados de uma formação intelectual crítica e cultural generalista, formulam e implementam propostas de enfrentamento das manifestações da "questão social", no conjunto das relações sociais e no mercado de trabalho (ASSOCIAÇÃO BRASILEIRA DE ENSINO E PESQUISA EM SERVIÇO SOCIAL [ABEPSS], 1996).

O conteúdo social é o objeto do Serviço Social nos seguintes termos:

Os assistentes sociais trabalham com a questão social nas suas mais variadas expressões quotidianas, tais como os indivíduos as experimentam no trabalho, na família, na área habitacional, na saúde, na assistência social pública. (IAMAMOTO, 1997, p. 14).

Para a autora, esse tema é a expressão das desigualdades e é a ele que os sujeitos resistem e se opõem, em um contexto de tensão, desigualdade e resistência, em que o cotidiano profissional dos/as assistentes sociais se realiza.

Sob essa percepção, a discussão acerca da identidade profissional da Assistente Social expressa as dimensões teórico-metodológica, ético-política, técnico-operativa e investigativa, inerente à intervenção profissional construída na prática cotidiana, na demanda dos usuários imigrantes atendidos nos CRAS.

Os/as usuários/as dos serviços socioassistenciais apresentam demandas singulares, possibilitando intervenções tanto no âmbito imediato quanto no mediato, por intermédio de ações elaboradas de forma articulada. A instrumentalidade do Serviço Social, aqui entendida como os meios pelos quais os profissionais realizam as mediações, é um processo historicamente construído, independentemente da perspectiva teórico-metodológica adotada.

As especificidades do atendimento social em região fronteiriça seguem as dinâmicas próprias do fluxo de pessoas que saem dos países de origem, para procurar, em outro, o atendimento das necessidades sociais.

Além da diferença cultural, social, econômica e estrutural entre os países integrantes do Mercosul, ambos (Brasil e Bolívia) possuem características peculiares: longa faixa de fronteira e dinâmicas locais de circulação de mercadorias, serviços e pessoas. No Brasil, são 588 municípios de 11 estados localizados em faixa de fronteira, sendo 122 limítrofes, com 32 cidades gêmeas, segundo dados do Instituto de Pesquisa Econômica Aplicada [IPEA] (2019). O estado de Mato Grosso do Sul possui sete cidades-gêmeas na fronteira com o Paraguai e com a Bolívia; seis municípios fazem fronteira com o Paraguai: Bela Vista, Coronel Sapucaia, Mundo Novo, Paranhos, Porto Murtinho e Ponta Porã. E apenas um faz fronteira com a Bolívia: Corumbá, que está ao lado de Puerto Quijarro (BOL).

O debate acerca da fronteira é eixo referencial, por impactar diretamente nas intervenções realizadas nesses espaços, necessitando, portanto, de uma definição que contemple as características inerentes. Na atualidade, é vasto o número de publicações referentes a esta questão, com diversas classificações de tipos de fronteira demonstrando a amplitude da discussão, pois esta evoca uma multiplicidade de sentidos.

Para compreender o trabalho social na região de fronteira, é necessário conhecer definições desse conceito diante da complexidade que o envolve, sendo fundamental na concepção das relações sociais, culturais, econômicas e políticas. 
A definição de fronteira, na Constituição Federal do Brasil (BRASIL, 1988), corresponde a uma "faixa de fronteira", ou seja, espaço de controle e uso restrito: "[...] de até cento e cinquenta quilômetros de largura ao longo das fronteiras terrestres [...] considerada fundamental para a defesa do território nacional, e sua ocupação e utilização serão reguladas por lei" (Artigo 20, parágrafo $2^{\circ}$ ).

A fronteira é, simultaneamente, lugar da alteridade e expressão da contemporaneidade dos tempos históricos. "A unidade do diverso, pressuposto metodológico da dialética, encontra aí o lugar mais adequado e mais rico para a investigação científica" (MARTINS, 1996, p. 25).

Martins (1996) formula uma definição das várias dimensões que compõem esta realidade:

A fronteira de modo algum se reduz e se resume à fronteira geográfica. Ela é fronteira de muitas e diferentes coisas: fronteira da civilização (demarcada pela barbárie que nela se oculta), fronteira espacial, fronteira de culturas e 35 visões de mundo, fronteira de etnias, fronteira da História e da historicidade do homem. E, sobretudo, fronteira do humano. (MARTINS, 1996, p. 13).

A contribuição de Foucher (2009) apresenta o contexto atual como um mundo sem fronteiras, de fluxos imigratórios contínuos, de trocas constantes, de interações que extravasam a dinâmica nacional, que se localizam na esfera internacional.

A mobilidade humana, vista como ocupação de diferentes lugares, bem como pela criação de vínculos sociais entre as pessoas, neutraliza o distanciamento geográfico e pode ser identificada nas fronteiras em movimento. É o caso de Corumbá, que apresenta, cotidianamente, um fluxo de residentes da conurbação que a envolve, como aborda Paixão (2006):

Por conta do distanciamento dos municípios que compõem essa região para com seus centros administrativos e financeiros nacionais, houve uma situação de contato maior entre os mesmos do que aquele estabelecido para com seus pares nacionais. Mesmo hoje, com a evolução dos transportes e dos meios de comunicação, as cidades bolivianas de Puerto Quijarro e Puerto Súarez, tanto quanto a de Ladário, no Brasil, tem buscado em Corumbá os bens e serviços de que não dispõem (PAIXÃO, 2006, p. 100).

Há também a percepção da necessidade de demarcação de limites geográficos como um mecanismo que assegura os países contra os perigos do caos. E, ainda, de que os limites internacionais permaneçam indicando as diferenças legais como o princípio da identidade territorial e a separação entre nacionais e não nacionais por meio de impedimentos jurídicos, políticos e ideológicos (RAFFESTIN, 1993 apud STEIMAN; MACHADO, 2002, p. 7). São exatamente compreensões como a de Raffestin (1993) que impõem regras e normas para a criação de um sistema de proteção social integrado nas regiões de fronteira, garantidor da concretude dos direitos sociais para além de barreiras físicas.

Para além do exposto, as situações que afligem as faixas de fronteira são colocadas como problemas locais particulares de cada cidade ou região fronteiriça, as quais são responsáveis por encaminhar estratégias locais de resolução. Nessa perspectiva, as cidades de fronteira, ou regiões, são tomadas pelas compreensões minimalistas de rotas de passagem para redes transnacionais, e não como espaços necessários e complementares para uma efetiva integração (SILVA, 2006, p. 105).

Já o "viver fronteiriço" se estende para muito além de limites geopolíticos e territoriais, pois se trata de um lugar prenhe de peculiaridades, trocas diversas, conflitos e contradições que moldam os profissionais e as pessoas envolvidas no cotidiano da fronteira. Como bem destaca Fedatto (2006): 
[...] entendemos a fronteira como uma realidade específica, marcada por uma identidade econômica e social que reflete, por um lado a intersecção das culturas de nações limítrofes e de outro, o desencontro das respectivas esferas político-administrativas nacionais. Nesse enfoque, é necessário reconhecer que, o corte imposto por uma linha de fronteira não representa uma descontinuidade cultural abrupta. Muito ao contrário, trata-se de uma zona, que podendo gerar conflitos, também emerge como áreas abertas a trocas de benefícios recíprocos entre povos vizinhos. (FEDATTO, 2006, p. 492).

De qualquer maneira, as linhas divisórias de um Estado-Nação que formam uma fronteira são resultantes da ação histórica dos seres humanos, ou seja, um espaço de práticas sociais, estando sujeitas a diversas alterações, em vários sentidos, seja na orientação do espaço como uma barreira, seja como um agente de integração regional.

Diante dessa conjuntura, é preciso estudar as particularidades do trabalho profissional do assistente social que apresenta novas dimensões identitárias diante das intervenções e implementação da garantia dos direitos sociais à população fronteiriça.

Na fronteira Brasil/Bolívia, a circulação² de pessoas no município de Corumbá demanda interferência imediata e mediata do serviço social em que a negação de direitos de cidadania se faz presente.

O atendimento ao/à estrangeiro/a no Brasil está garantido por intermédio da convenção sobre os estrangeiros (BRASIL, 1929, tradução nossa), do qual o Brasil é signatário:

Que os Estados devem conceder aos estrangeiros domiciliados ou de passagem em seu território todas as garantias individuais que concedem nos seus próprios nacionais e o gozo dos direitos civis essenciais, sem prejuízo, no que concerne aos estrangeiros, das prescrições legais relativas a extensão e modalidades do exercício dos ditos direitos e garantias ${ }^{3}$.

Assim, são essenciais a promoção e a garantia dos Direitos Humanos de pessoas vulneráveis, hipossuficientes, como muitas vezes é o caso de trabalhadores imigrantes, buscando combater a discriminação e o preconceito, a partir da utilização dos meios existentes para a concreta implantação de tais direitos. Os Estados têm o dever proporcionar meios apropriados em plano nacional, principalmente, nas searas da educação, da saúde e da assistência social, com intuito de promover e garantir os direitos das pessoas hipossuficientes.

As atividades realizadas no campo da temática migratória advêm das atribuições do governo federal no tocante à Política Nacional de Assistência Social por meio do Ministério do Desenvolvimento Social e Combate à Fome. O fenômeno da mobilidade humana exige respostas transversais no âmbito das políticas públicas e envolve diversas pastas, como possibilidade de um resultado efetivo.

Diante desse cenário, cabe salientar que a recepção e a integração da população estrangeira no território nacional ultrapassam a responsabilidade da Rede de Assistência Social do Brasil, por

\footnotetext{
${ }^{2}$ Circulação de pessoas característica nas cidades fronteiriças de Corumbá, MS, e Puerto Suárez, BOL, devido ao movimento pendular que é compreendido no deslocamento diário, principalmente de trabalhadores que residem em uma cidade e trabalham em outra.

${ }^{3}$ Tradução da autora baseado no trecho original da convenção sobre os estrangeiros (BRASIL, 1929): "ARTíCULO 5․ Los Estados deben reconocer a los extranjeros domiciliados os transeuntes en su territorio todas las garantías individuales que reconocen a favor de sus propios nacionales y el goce de los derechos civiles esenciales, sin perjuicio, en cuanto concierne a los extranjeros, de las prescripciones legales relativas a la extención y modalidades del ejercicio de dichos derechos y garantías".
} 
envolver questões de direitos humanos, jurídicas, trabalhistas, de segurança pública, educação, saúde e seguridade social.

A Política Nacional de Assistência Social prevê o ordenamento dos serviços em rede de acordo com os seguintes tipos de proteção social: básica e especial (de média e alta complexidade). A Proteção Social Básica reúne um conjunto de serviços, programas, projetos e benefícios da assistência social estruturados para prevenir situações de vulnerabilidade social e risco pessoal e social. Destina-se à população que tem acesso precário ou nulo aos serviços públicos, fragilização de vínculos afetivos e comunitários ou discriminações (etárias, étnicas, de gênero ou por deficiências), entre outras. Independentemente da nacionalidade, o atendimento aos migrantes deve estar garantido em todos os níveis de proteção, de acordo com as demandas apresentadas. A unidade de referência nos territórios para oferta de atenção no âmbito da proteção básica é o CRAS.

Conforme a Política Nacional de Assistência Social (PNAS), o CRAS é uma unidade pública municipal de assistência social localizada em área de maior índice de vulnerabilidade e risco social. Esta instituição presta serviços e desenvolve programas socioassistenciais no âmbito da proteção social básica às famílias, promove a articulação destes serviços no território de abrangência visando potencializar a proteção social e atuando na perspectiva da intersetorialidade.

O CRAS é também uma unidade efetivadora da referência e contrarreferência do usuário na rede socioassistencial do SUAS, bem como da referência para os serviços das demais políticas públicas. O CRAS é a "porta de entrada" dos usuários na rede de proteção social básica do SUAS. A PNAS 2004 e a Norma Operacional Básica (NOB) 2005 trouxeram ao país o desafio da implementação do Sistema Único de Assistência Social (SUAS); a organização e a estruturação de serviços, benefícios, programas e projetos socioassistenciais. O compromisso mais atual colocado ao SUAS para assegurar a institucionalidade da política de Assistência Social no Brasil se refere ao aprimoramento da gestão e à qualificação da oferta de serviços.

As formas de acesso ao CRAS ocorrem por demanda espontânea (quando o usuário vai até a unidade por meios próprios buscar informações, atendimentos, atualização de Cadastro Único etc.), por busca ativa (quando a equipe técnica da unidade se desloca até o usuário), por encaminhamento da rede socioassistencial (outros equipamentos da rede enviam relatório solicitando atendimento para a família), por direcionamento das demais políticas públicas.

Segundo o Decreto n. 7.334/2010 (BRASIL, 2010), em que se institui o Censo do Sistema Único de Assistência Social (Censo SUAS), destacam-se também como atividades a serem realizadas: a acolhida particularizada e em grupo; o acompanhamento e a elaboração do plano de acompanhamento familiar; o registro de acompanhamento familiar em prontuário; grupo/ oficina com famílias; visitas domiciliares; palestras; campanhas ou eventos comunitários; apoio para obtenção de documentação pessoal; encaminhamento de famílias ou indivíduos para a rede de serviço socioassistencial, para obtenção de benefícios eventuais, para inserção/atualização de famílias no Cadastro Único e para outras políticas públicas, tais como educação, habitação e trabalho.

Entre os serviços, estão encaminhamentos para documentação; cadastro para solicitação de benefícios eventuais; oficinas; cadastro único; serviço de convivência e fortalecimento de vínculos; e cursos de capacitação para geração de renda. Este último, por meio do Acessuas Trabalho, iniciativa da Política Nacional de Assistência Social para promover o acesso dos usuários a oportunidades do mundo do trabalho, com ações integradas e articuladas voltadas para a garantia dos direitos e a cidadania das pessoas em situação de vulnerabilidade social. 
Nos municípios onde há presença de migrantes, é importante destacar o planejamento de ações que buscam incorporar esse público nos serviços, facilitando a criação de vínculos com a comunidade local e diminuindo a vulnerabilidade. Como é o caso do CRAS em questão em que há forte presença de famílias bolivianas participantes dos serviços ofertados.

Para a assistência social, o migrante é reafirmado como sujeito de direitos socioassistenciais independente da regularidade da sua situação migratória. Os mesmos direitos socioassistenciais e as mesmas seguranças sociais afiançadas pelo SUAS para os brasileiros devem estar garantidos aos migrantes e refugiados.

O Ministério do Desenvolvimento Social publicou em 2016 o documento "O Papel da Assistência Social no Atendimento aos Migrantes", em que aponta que o atendimento aos migrantes deve estar garantido em todos os níveis de proteção, de acordo com as demandas apresentadas.

A oferta destes serviços pressupõe a necessária atenção à intersetorialidade e ao trabalho em rede, que vai além da Proteção Social Básica, sendo fundamental a articulação com as demais políticas sociais e com órgãos de defesa de direitos (Poder Judiciário, Ministério Público, Conselhos Tutelares).

Ainda que a política de assistência social seja um campo de trabalho multiprofissional e interdisciplinar, ela se constitui historicamente como uma das principais mediações do exercício profissional dos/as assistentes sociais, sendo reconhecidos socialmente (e se autorreconhecendo) como os profissionais de referência desta política, apesar das ambiguidades que cercam essa relação de longa data.

Orientar o trabalho do assistente social nos rumos aludidos requisita um perfil de profissional crítico e capaz de formular, recriar e avaliar propostas norteadoras para a progressiva democratização das relações sociais. Exige-se, para tanto, compromisso ético-político com os valores democráticos e competência teórico-metodológica na teoria crítica, em sua lógica de explicação da vida social. Esses elementos, aliados à pesquisa da realidade profissional, possibilitam decifrar as situações particulares com que se defronta o assistente social no trabalho, de modo a conectá-las aos processos sociais macroscópicos que as geram e as modificam.

Por fim, não é possível falar em uma única identidade para o Serviço Social. Como recomenda Gentilli (1997), entende-se que, partindo das políticas sociais, colocando-as em prática, pode-se encontrar caminhos para definir as identidades enquanto profissionais, embora construção e sedimentação aconteçam em todo o processo formativo.

\section{CONSIDERAÇÕES FINAIS}

Assim, objetivando acrescer elementos quanto à discussão da identidade profissional da assistente social e as ações no território de atuação, conclui-se que, para além da prática profissional, acontecem as transformações, cotidianamente, ancoradas nos sujeitos atendidos e nas demandas pelo serviço social, conforme o momento social, posto que determinam e constroem as necessidades no modo de produção capitalista.

A concepção de fronteira como um lugar, na percepção dos autores, que evoca uma multiplicidade de sentidos, de fluxos migratórios contínuos, interações e trocas econômicas e culturais, repleto de contrastes e contradições, torna ainda mais relevante a prática profissional nesses espaços.

INTERAÇÕES, Campo Grande, MS, v. 22, n. 3, p. 803-817, jul./set. 2021. 
Expor o trabalho desse profissional, com uma visão sociopolítica por intermédio de um projeto ético-político junto a políticas públicas, transforma a reflexão acerca da demanda atendida e direciona o fazer profissional.

Nesse sentido, a atividade das assistentes sociais em região fronteiriça ultrapassa as fronteiras, ressignificando o exercício profissional de forma crítica e reflexiva em sua totalidade, fazendo repensar as práticas e os atendimentos da população em condição de vulnerabilidade econômica, entre outras mazelas sociais, sendo possível a (re)definição de identidades das profissionais da fronteira.

\section{REFERÊNCIAS}

ASSOCIAÇÃO BRASILEIRA DE ENSINO E PESQUISA EM SERVIÇO SOCIAL [ABEPSS]. Diretrizes Curriculares para o Curso de Serviço Social. Brasília-DF: ABEPSS, 1996. (mimeo).

BRASIL. Código de ética do/a assistente social: Lei 8.662/93 de regulamentação da profissão. 9. ed. rev. e atual. Brasília-DF: CFSS, 2011.

BRASIL. Decreto n. 7.334/2010, de 19 de outubro de 2010. Institui o Censo do Sistema Único de Assistência Social - Censo SUAS, e dá outras providências. Brasília-DF, 2010.

BRASIL. Lei n. 8.662, de 7 de junho de 1993. Dispõe sobre a profissão de Assistente Social e dá outras providências. Brasília-DF, 1993.

BRASIL. Constituição da República Federativa do Brasil. Brasília-DF, 1988.

BRASIL. Decreto n. 18.956, de 22 de outubro de 1929. Promulga seis convenções de direito internacional publico, approvadas pela Sexta Conferencia internacional americana. Brasília-DF, 1929. Disponível em: http://www2.camara.leg.br/legin/fed/decret/1920-1929/decreto-18956-22-outubro1929-549004publicacaooriginal-64267-pe.html. Acesso em: 14 out. 2021.

CASTELLS, Manuel. O poder da identidade. São Paulo: Paz e terra, 2002. (A era da informação: economia, sociedade e cultura, v. 2).

CORRÊA, Jaqueline Maciel. O mestrado profissional em estudos fronteiriços em perspectivas de inserção social: avaliações sobre a implantação do circuito de apoio ao imigrante. 2016. 89 f. Dissertação (Mestrado em Estudos Fronteiriços) - Universidade Federal de Mato Grosso do Sul, Corumbá, MS, 2016.

FEDATTO, Nilce. Educação em Mato Grosso do Sul: limitações da escola brasileira numa divisa sem limites na fronteira Brasil-Paraguai. In: OLIVEIRA, Tito Carlos Machado (Org.). Território sem limite. Campo Grande: UFMS, 2006.

FILARTIGAS, Danilo Magno Espindola. Migrações na fronteira: ações e perspectivas da Polícia Federal. 2014. Dissertação (Mestrado em Estudos Fronteiriços) - Universidade Federal de Mato Grosso do Sul, Corumbá, MS, 2014.

FOUCHER, Michel. Obsessão por fronteiras. São Paulo: Radical Livros, 2009.

GENTILLI, Raquel de Matos Lopes. A prática como definidora da identidade profissional do Serviço Social. Serviço Social \& Sociedade, São Paulo, v. 18, n. 53, p. 126-44, mar. 1997.

GIOVANELLA, Lígia. Saúde nas fronteiras: estudo do acesso aos serviços de saúde nas cidades de fronteira com países do MERCOSUL. Rio de Janeiro: ENSP; Fiocruz, 2007. 
HOFLING, Eloisa de Mattos. Estado e políticas (públicas) sociais. Cadernos Cedes, Campinas, v. 21, n. 55, p. 30-41, nov. 2001.

IAMAMOTO, Marilda Vilela. O serviço social na contemporaneidade: trabalho e formação profissional. 10. ed. São Paulo: Cortez, 2006

IAMAMOTO, Marilda Vilela. O Serviço Social na contemporaneidade: dimensões históricas, teóricas e ético-políticas. Fortaleza: CRESS, 1997. (Debate n. 6).

INSTITUTO DE PESQUISA ECONÔMICA APLICADA [IPEA]. Ipea, 2019. Página inicial. Disponível em: http:// www.ipea.gov.br. Acesso em: 22 jul. 2019.

MARTINELLI, Maria Lúcia. A pergunta pela identidade profissional do Serviço Social: matriz de análise. Revista Serviço Social \& Saúde, Campinas, v. 2, p. 155-65, 2013.

MARTINELLI, Maria Lúcia. Serviço Social: identidade e alienação. 6. ed. São Paulo: Cortez, 2000. p. 17.

MARTINS, José de Souza. O tempo da fronteira: retorno à controvérsia sobre o tempo histórico da frente de expansão e da frente pioneira. Tempo Social, São Paulo, v. 8, n. 1, p. 25-70, 1996.

NETTO, José Paulo. Ditadura e serviço social: uma análise do serviço social no Brasil pós-64. 5. ed. São Paulo: Cortez, 2001.

LOIO, Joanna Amorim de Melo; MARINI, Joyce Ferreira de Melo; OLIVEIRA, Marco Aurélio Machado. Imigrantes bolivianos da planície e do altiplano em região de fronteira: distinções pregressas em solidariedade seletiva. Revista Geopantanal, Corumbá, v. 17, n. especial, p. 219-32, 2017.

OLIVEIRA, Marco Aurélio Machado; CORRÊIA, Jacqueline Maciel; OLIVEIRA, Jéssica Canavarro. Imigrantes pendulares em região de fronteira: semelhanças conceituais e desafios metodológicos. Revista Direito Cultural, Santo Ângelo, v. 12, n. 27, p. 91-108, 2017.

OLIVEIRA, Tito Carlos Machado. Para além das linhas coloridas ou pontilhadas: reflexões para uma tipologia das relações fronteiriças. Revista da Associação Nacional de Pós-graduação e Pesquisa em Geografia (Anpege), Paraíba, v. 11, n. 15, p. 233-56, jan./jun. 2015. doi: https://doi.org/10.5418/RA2015.1115.0009

PAIXÃO, Roberto Ortiz. Globalização, turismo de fronteira, identidade e planejamento da região internacional de Corumbá, MS. 2006. Tese (Doutorado em Geografia Humana) - Universidade de São Paulo, São Paulo, SP, 2006.

PEITER, Paulo Cesar. Geografia da Saúde na faixa da fronteira continental do Brasil na passagem do milênio. 2005. Tese (Doutorado em Geografia) - Universidade Federal do Rio de Janeiro, Rio de Janeiro, RJ, 2005.

RAFFESTIN, Claude. Por uma geografia do poder. São Paulo: Editora Ática, 1993.

STEIMAN, Rebeca; MACHADO, Lia Osório. O. Limites e fronteiras internacionais: uma discussão históricogeográfica. Rio de Janeiro: Grupo Retis; UFRJ, 2002.

SILVA, Maria Geusina. O local e o global na atenção as necessidades de saúde dos brasiguaios: análise da intervenção profissional do Assistente Social em Foz do Iguaçu. 2006. Dissertação (Mestrado em Serviço Social) - Universidade Federal de Santa Catarina, Florianópolis, SC, 2006.

SILVA, Rosangela Villa; FERREIRA, Stael Moura Paixão. A identidade fronteiriça Brasil-Bolívia: um estudo sobre Linguagem na Literatura de Fronteira. Diamantina. Revista Multidisciplinar Acadêmica Vozes dos Vales, Minas Gerais, v. 2, n. 4, p. 1-15, 2013. 
UOL. Mapa Bolívia e Brasil. UOL, [s.l.], 2013. Disponível em: https://conteudo.imguol.com.br/c/ noticias/2013/08/26/mapa-bolivia-e-brasil-1377530807586_300x300.gif. Acesso em: 14 out. 2021.

\section{Sobre as autoras:}

Natália Buginga Ramos da Costa Sachini: Mestre em Estudos Fronteiriços pela Universidade Federal de Mato Grosso do Sul (UFMS). Especialista em Serviço Social e Gestão de Projetos Sociais pela Universidade Anhanguera São Paulo; e em Gestão Social: Políticas Públicas, Redes e Defesa de Direitos pela Universidade do Norte do Paraná (UNOPAR). Graduada em Serviço Social pela Universidade Federal Fluminense (UFF). Atualmente é Assistente Social da Prefeitura Municipal de Corumbá, Mato Grosso do Sul. E-mail: natalia_buginga@hotmail.com, Orcid: https://orcid.org/0000-0001-8503-8208

Mara Aline Ribeiro: Doutora em Geografia pela Universidade Estadual de Campinas (UNICAMP). Mestre em Educação pela Universidade Federal de Mato Grosso do Sul (UFMS). Licenciada e bacharela em Geografia pela Universidade Federal de Mato Grosso do Sul (UFMS). Atualmente é professora adjunta na UFMS. E-mail: mara_aline@yahoo.com.br, Orcid: http://orcid.org/0000-0002-4693-4656 
